\title{
Potentials of Preparation for Reuse: A Case Study at Collection Points in the German State of Bavaria
}

\author{
Lukas Messmann*,a, Sandra Boldoczkia ${ }^{\text {, Andrea Thorenz }}{ }^{\mathrm{a}}$, Axel Tuma ${ }^{\mathrm{a}}$ \\ *Address correspondence to: lukas.messmann@wiwi.uni-augsburg.de \\ ${ }^{a}$ Resource Lab, Institute of Materials Resource Management, University of Augsburg, \\ Universitaetsstr. 16, 86159 Augsburg, Germany \\ Published in: Journal of Cleaner Production 211 (2019), 1534-1546. \\ https://doi.org/10.1016/j.jclepro.2018.11.264
}

\begin{abstract}
This research addresses the second priority of the waste management hierarchy and the demand for a circular economy. First, we develop a methodology for the quantitative assessment of potentially reusable wastes. Second, based on empirically retrieved primary data following the developed methodology, this study quantifies a theoretical potential for the preparation for reuse of Waste Electric and Electronic Equipment (WEEE), used furniture, and used leisure goods in the German state of Bavaria. We find that between $13 \%$ and $16 \%$ of these waste streams could immediately be prepared for reuse, depending on the type of waste. A further potential of $13 \%$ to $29 \%$ could be unlocked through changes to the mode of collection, storage and the overall treatment of wastes at Bavaria collection points. Most notably, $86 \%$ of identifiable damage causes of WEEE are attributed to a lack of sufficient weatherproof roofing. Conclusively, we derive four key action recommendation for unlocking existing potentials.
\end{abstract}

\section{Keywords}

Preparation for reuse, Reuse potential, Circular economy, Waste management, Transfer station 


\section{Introduction}

Natural resource depletion pressures all corporate, societal and political stakeholders to establish resource efficient structures. Besides industry policies and resource initiatives, the EU's definition of preparation for reuse as the second priority of the EU waste management hierarchy is an important step towards realizing that goal. Preparation for reuse includes recovery operations of end-of-life products, which enable the recirculation of those products into the use-phase. It provides ecological and economic benefits simultaneously: Reusing products extends their lifetime and reduces the raw material required for new products. Thus, reuse has the potential to save resources, emissions, and energy (Lapkin et al., 2004). Likewise, lifetime extension diminishes the generation of waste and therefore negative impacts on health and environment associated with it (Hutner et al., 2018). Depending on the condition of a used product and the preparation effort needed for reuse, a reduced purchase price may render the item affordable for those who are not able to afford a new product. In addition, assuming a regional reuse scenario, preparation efforts may lead to local employment. Therefore, reuse has the potential to offer additional social and economic benefits (Pladerer et al., 2008; Devoldere et al., 2009; O'Connell et al., 2012).

In Germany, the Law on Closed Cycle Management and Waste (Kreislaufwirtschaftsgesetz, KrWG) enforces the waste management hierarchy on the national level and is intended to tighten resource, climate and environmental protection regulations with the goal of protecting human health and the environment (KrWG \$1) in alignment with the principles and goals of a circular economy (Ghisellini et al., 2016). Following the EU Waste Framework Directive (Directive 2008/98/EC), preparation for reuse and recycling of municipal waste must account for 65\% by January 1st 2020 (KrWG §14). To our knowledge, no sufficient data basis, indicating the potential of wastes that could be spared from recycling and instead be prepared for reuse, is existent for Bavaria or other states of Germany or the European Union up to now (European Commission, 2015).

Addressing the aforementioned lack of data needed for the enforcement of the waste management hierarchy, our quantitative empirical study assesses the potentials of different waste streams for the preparation for reuse based on primary data acquisition at 61 collection points $^{1}$ in the German state of Bavaria. In order to account for waste stream specific modalities for waste collection, disposal and management, we distinguish between the three waste streams waste electric and electronic equipment (WEEE), used furniture and leisure goods.

This study, funded as part of a research project by the Bavarian State Ministry of the Environment and Consumer Protection since 2016, sets out to answer the following research questions:

* What is the quality of different waste streams in different classes of municipalities and what are the causes of damages?

\footnotetext{
1 In this study, the term collection point (German Wertstoffhof) refers to sites operated by public waste management authorities for the collection and temporary deposition of either bulky wastes that municipal waste collection schemes cannot collect, or wastes that contain hazardous or recoverable materials. This concept is sometimes also referred to as transfer station, civic amenity site, or household waste recycling center.
} 
* What is the resulting theoretical potential for the preparation for reuse in Bavaria?

* Which actions recommendations result from the main obstacles to realizing this potential at Bavarian collection points?

Section 2 gives an account of European and German waste management legislation and current practice in the German state of Bavaria, and describes the state of the art in this particular field of research. Section 3 comprises an outline of our method and the empirical approach, as well as a description of the three assessed waste streams and the procedure of data collection. In Section 4, we analyze collected primary and secondary data, and derive insights from this analysis in section 5 . This study concludes in section 6 , where we delineate our follow-up research agenda.

\section{Legal context and state of the art}

With the European Waste Framework Directive (Directive 2008/98/EC) coming into effect in 2008, waste prevention takes priority in the waste hierarchy for all EU member states, and is aimed at goods that have not yet passed the waste threshold (Figure 1). Approaches for waste prevention can be assigned to the four categories reduction at source, substitution, intensification of use, and lifetime extension. Direct reuse is considered an extension of lifetime and therefore attributes to a measure of waste prevention (Hutner et al., 2017). When the owner of a product disposes of it or expresses the will to dispose (KrWG §3), the product passes the waste threshold and turns into waste. Beyond the waste threshold, preparation for reuse is the preferred waste management option. If preparation for reuse is not feasible, goods are eligible for disassembly and the recycling of its materials. If goods cannot be recycled, the next option is energetic recovery, e.g. waste-to-energy. All of the aforementioned waste management options are preferable over disposal and landfilling.

For instance, the percentage of processed WEEE in Germany amounts to $90.3 \%$ in 2015, which implies a disposal fraction of $9.7 \%$. Recycling is by far the most prevalent form of recovery with $78.8 \%$. Furthermore, another $11.0 \%$ are recovered energetically. Consequently and despite its prominent status within the waste hierarchy, preparation for reuse only covers an almost negligible fraction of 0.5\% (BMUB, 2015; see section 4.4).

Waste prevention

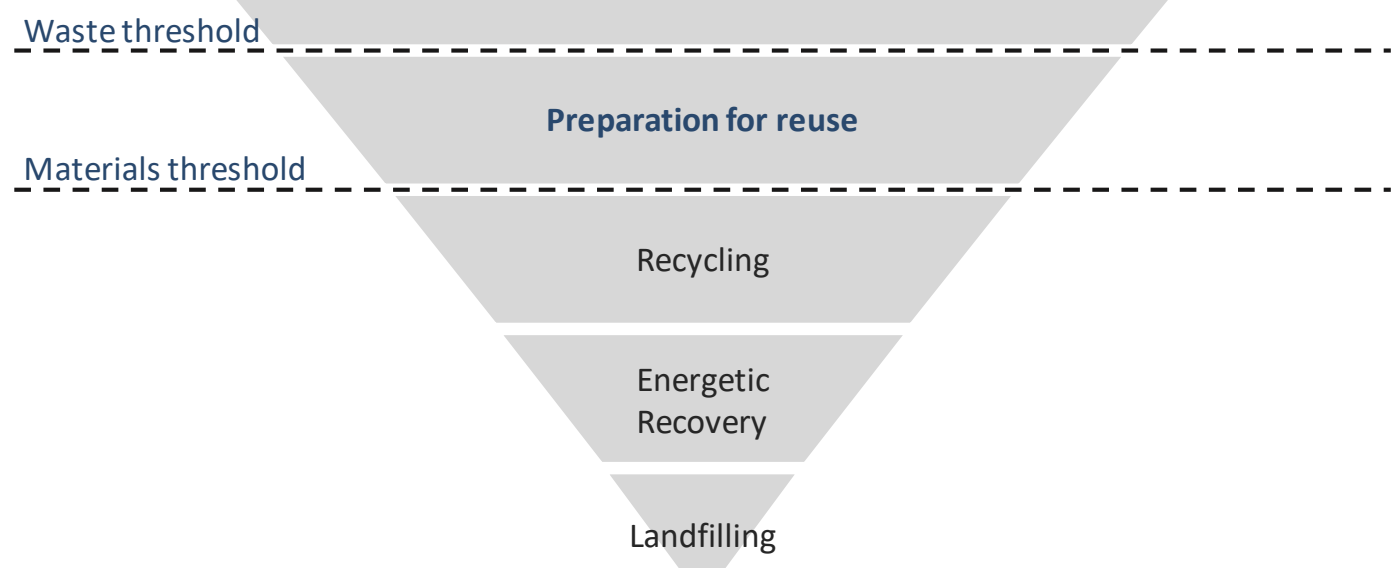


Figure 1. Waste hierarchy according to the EU Waste Framework Directive

This research thus addresses the second priority of the waste management hierarchy. The recovery operations required for the recirculation of waste into the use-phase comprise examination, cleaning, and repairing (KrWG §3). A study of the German Federal Environmental Agency identifies manufacturers and repair facilities as commercial actors of the supply chain, and municipal disposal as well as social-charitable institutions as non-commercial ones (Schomerus et al., 2014).

According to German federal law, municipalities are in charge of waste management (UBA, 2014). The waste collection and registration system comprises a pick-up system and a bring system (LfU, 2016). Within the pick-up system, municipal disposal services collect household wastes. The bring system consists of waste specific public containers (glass, textiles and WEEE) and collection points, where citizens can dispose of products that are not feasible for pick-up, either due to their size or the incorporation of hazardous or recoverable components. This can be bulky waste (e.g. furniture or leisure goods), electric appliances (e.g. white goods), paper, as well as bio or construction waste. Waste arriving at collection points should thus yield by far the highest potential for the preparation for reuse, compared to wastes collected by the pick-up system or public containers. The preeminence of collection points compared to other disposal routes is also observed in Denmark (Parajuly and Wenzel, 2017) and England (Curran et al., 2007; WRAP, 2011).

Management practices for WEEE vary strongly within different countries as analyzed by Ongondo et al. (2011). In Europe, the collection of WEEE is subject to Extended Producer Responsibility (EPR) as defined by the European Directive on Waste Electrical and Electronic Equipment (Directive 2012/19/EU), according to which producers are responsible for take-back, treatment, and recycling of WEEE. The incentives initiated by ERP mainly focus on the recycling of materials and are rarely involved with the operations related to the preparation for reuse (Grunow and Gobbi, 2009; Kunz et al., 2018; Zacho et al., 2018). Charitable institutions conduct the major part of processing municipally collected waste for the preparation for reuse (Sander et al., 2013; Schomerus et al., 2014), but the overall amount of goods undergoing recovery operations for remarketing is minimal. Johnson et al. (2015) and Queiruga and Queiruga-Dios (2015) identify a strong need for a distinct quota for reuse, since legislation promotes the preparation for reuse as the preferred waste management option compared to recycling, which is contrary to current practice. Existing research (Guerra González, 2013; Sander et al., 2013; Schomerus et al., 2014) analyzes organizational structures, the legal framework, and generic recommendations for enforcing the second priority of the waste hierarchy on a qualitative basis, targeting almost exclusively WEEE. Pérez-Belis et al. (2015) conducted an in-depth literature review focusing on inter alia management, generation, characterization, and reuse of WEEE, but state that "further case studies are needed in countries that practice greater reuse" (Queiruga and QueirugaDios, 2015).

CIWM (2016) describe the status quo of reuse in the UK and derive recommendations for industry and government. For the German market, von Gries and Henning (2017) quantify the annual amounts of WEEE, furniture, and textiles that are already reused or prepared for reuse. A great body of literature addresses challenges that currently hinder the preparation for reuse and restrict the access to sufficient volumes of reusable goods. Commonly mentioned are improvements in legislation (Ongondo 
et al, 2011; Guerra González, 2013; Kissling et al., 2013; Sander et al., 2013; European Commission, 2015; Johnson et al., 2015; CIWM, 2016; Löhle et al., 2016), consumer communication and information (Neitsch et al., 2010; Sander et al., 2013; the European Commission, 2015; CIWM, 2016; Löhle et al., 2016), cross-sector engagement (Spitzbart et al., 2009; Neitsch et al., 2010; Sander et al., 2013; Johnson et al., 2015; CIWM, 2016; Löhle et al., 2016) and improvements in the organizational structures on site. Concerning the latter, which is the focus of this study, Neitsch et al. (2010), BroehlKerner et al. (2012), Sander et al. (2013), and the European Commission (2015) identify missing qualification of employees at recovery centers, the considerable time demand, as well as an insufficient infrastructure as main barriers for preparation for reuse. Johnson et al. (2015) point out that an early separation of reusable devices at collection points is an important success factor for the preparation for reuse, and examine best-practice examples across Europe. The importance of value conserving logistics is emphasized by Kissling et al. (2013) and Parajuly and Wenzel (2017). Concerning research actions, it is agreed that standardized and more transparent methods for the documentation of end-of-life waste streams would strongly support reuse incentives (Ongondo et al., 2011; Parajuly and Wenzel, 2017).

A previous study on the reuse potential of bulky waste finds that $44 \%$ (by weight) of WEEE, and $37 \%$ of furniture and leisure goods disposed of at UK collection points are viable for reuse, based on estimations of residents. A visual inspection of the items by a site official resulted in a higher estimation of the reuse potential for WEEE (63\%) and furniture (48\%), but a lower fraction (24\%) for leisure goods (WRAP, 2012). The assessment via survey differentiates between reusable, non-reusable and unknown, whereas the visual inspection supplements information about the quality (reusable in current condition, slight repair required, or major repair work required) of the product (WRAP, 2012). A survey among 1450 households in England suggests reuse potentials of $59 \%$ for furniture, $49 \%$ for WEEE and, $9 \%$ for other bulky waste items (Curran et al., 2007). Bovea et al. (2016) outline a general methodology for assessing the reuse potential of small WEEE that could be repaired by repair enterprises. For the visual inspection, six mandatory criteria are defined (incomplete casing, missing elemental components, rusted parts, out of order, hygiene factors, and non-standardized pieces). Subsequently, a functionality and safety test is carried out. Out of a sample of 96 items, $68 \%$ are classified as potentially reusable. Parajuly and Wenzel (2017) investigate the reuse and recycling market potential of small WEEE and monitors in Denmark. Items are classified as "working fine" $22 \%$ of small WEEE and 7\% of monitors), "working with issues" and "not working" by a functionality test, after passing a visual inspection regarding the state of the product (complete, missing parts, or broken), and appearance (new, medium, or old). Based on the resale value of the items, the authors acknowledge a high reuse potential (Parajuly and Wenzel, 2017). All studies agree that the existing potential is not exploited. Nevertheless, except for an approach in the UK (WRAP, 2012), previous literature only focuses on selected WEEE, and a quantification of the reuse potential of bulky waste on state level is not existent (Haas et al., 2015). This greatly hinders the realization of reuse in practice. Additionally existing research assesses the reusability of goods, but the cause of damage is often neglected. We deem this information to be crucial for tackling the most pressing issues for the realization of existing potentials. 
Therefore, we follow a structured approach for the assessment of the potential for preparation for reuse. The data compiled in this study serves as an aid for the formulation of a preparation for reuse quota by politics, and supports the selection of effective actions to increase the processed amounts. Furthermore, the developed methodology for the assessment of potentials for reuse may serve as a template and may be refined and applied by academia and practitioners

\section{Method}

Our methodological approach follows three phases, subdivided into eight steps (Figure 2). The first phase frames our research aim and operationalizes the research question into three distinct fields of interest: status quo, potentials, and challenges of preparation for reuse. While the status quo of preparation for reuse can be derived from secondary data sources such as national statistics, primary data is necessary for the quantification of reuse potentials, due to a lack of data in existing literature. Therefore, in the second research phase, we collect primary data for three waste streams waste electric and electronic equipment (WEEE), used furniture and leisure goods. The empirical approach of the quantitative empirical study evolves from expert discussions within the project steering board. Simultaneously, we obtain secondary data to assess the amount of goods currently prepared for reuse (status quo) and the annual volume of total collected items in Bavaria. In the third phase, we analyze the compiled data record in terms of the collected amounts, the quality of items and item-specific reasons for damages. Combining primary and secondary data, we quantify a theoretical potential for the preparation for reuse of each waste stream, identify the foremost challenges, and derive action recommendations for each waste stream in different types of municipalities.

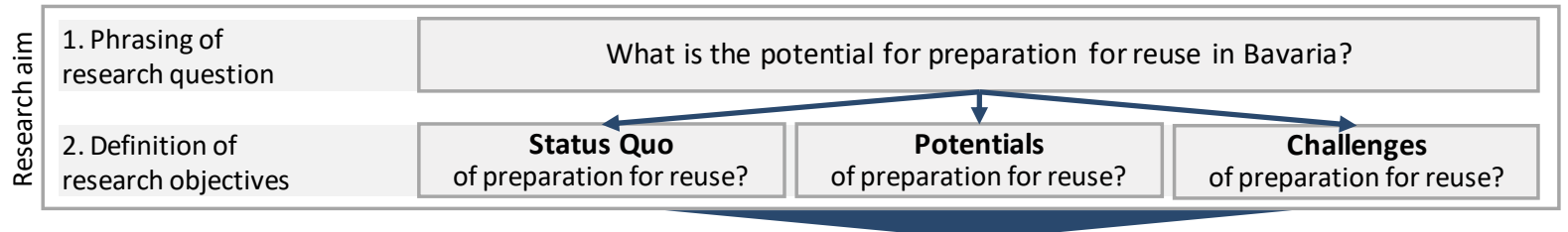

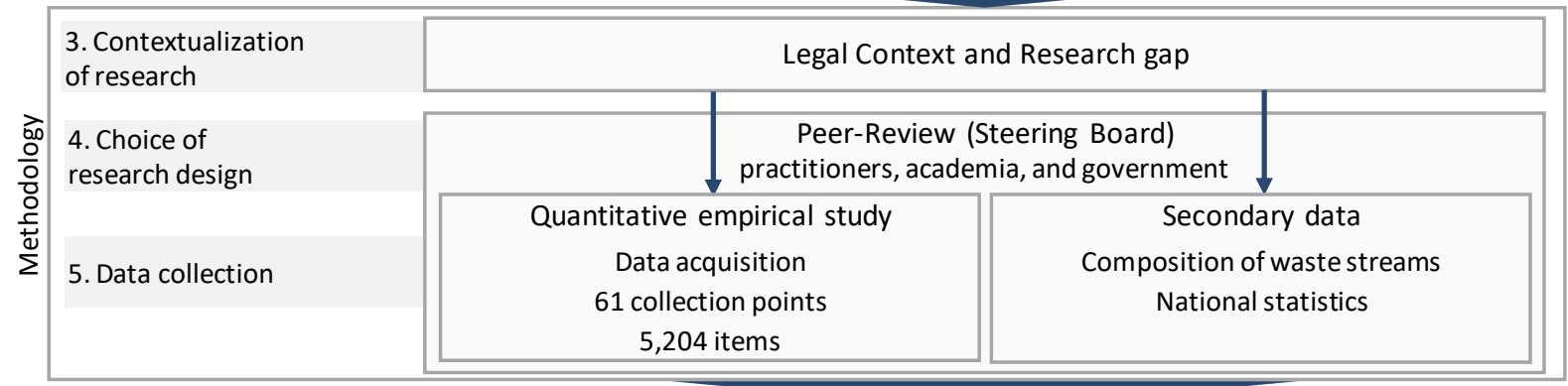

\begin{tabular}{|l|l|}
\hline 6. Data analysis & Amounts \\
\hline \multirow{2}{*}{\begin{tabular}{l|l|}
\hline 7. Interpretation \\
8. Deduction of Conclusions
\end{tabular}} \\
\cline { 2 - 3 }
\end{tabular}

Figure 2. Methodological approach for the assessment of potentials for preparation for reuse 


\subsection{Primary data collection}

In the primary data acquisition, we assess three waste streams. Due to its significant environmental footprint (Quariguasi Frota Neto et al., 2010), and potentially hazardous or precious constituents, WEEE is a waste stream of high interest in the European Union (Eurostat, 2018). The Directive on Waste Electrical and Electronic Equipment (Directive 2012/19 /EU) divides WEEE into six categories, which we, for the purpose of this study, further divide into small (screens and monitors, lamps, small equipment, and small IT equipment) and large WEEE (temperature exchange equipment, large equipment). Used furniture, by contrast, are often not listed as a distinct waste stream in waste statistics (e.g. LfU, 2016). We included used furniture due to its relevance for second-hand stores, its significance at collection points, especially in terms of volume, and its different nature compared to WEEE. Dehoust et al. (2006) give material fractions of waste furniture, of which wood is by far the most prevalent with $60 \%$ by weight. Lastly, there is no official definition or waste stream designation of "leisure goods"; hence, the category was introduced in this research project to enable the collection of data for goods such as bicycles, skis, other sports equipment, toys, instruments, and similar articles that are not also classified as WEEE or furniture.

We acquire primary data at 61 collection points. The data acquisition comprises an assessment of the quality of goods, the cause of damage, and the weight for each waste stream. A detailed list of collection points is given in Appendix B. They are located in densely populated urban (12), urban (14), densely populated rural (18) and rural (17) classes of municipalities. This characterization follows the classification of municipalities as used by the Bavarian Environmental Agency (LfU, 2016):

- densely populated urban municipality:

- urban municipality:

- densely populated rural municipality:

- rural municipality:
$>1,750$ inhabitants per $\mathrm{km}^{2}$
$>500$ inhabitants per $\mathrm{km}^{2}$
$>125$ inhabitants per $\mathrm{km}^{2}$
$\leq 125$ inhabitants per $\mathrm{km}^{2}$

On average, we visited each collection point for 3.0 hours on a weekday (Appendix B). Williams and Taylor (2004) find some differences between weekends and weekdays in the quantity of wastes that are disposed of in recycling centers in England. However, for this study, the differences in quantities are less relevant than the distribution of weights, qualities, and damage causes between collection points and municipalities. We aim at assessing collection points as sources for the preparation for reuse; therefore, we assess only those items that are already present at a collection point. This includes everything from crammed containers with mostly broken items, to collection areas for well-preserved equipment. This resulted in appx. 183 hours per person, or 366 person hours in total. Driving times account for additional 149 person hours. As pointed out in section 2, most of the existing literature comprises focused studies of single or a couple of collection points. Visiting 61 collection points for a comparably small time results in a relatively inefficient ratio of items per time unit. In this research project, however, the identification of differences between different classes of municipalities is an explicit research goal and necessitates a broader scope.

The same two persons carry out the data acquisition for every collection point. One alternative, i.e. collection point personnel carrying out the acquisition, would be more efficient in terms of the ratio between time spent and items observed. However, our approach increases the consistency of the data. Both a scientific background as well as a technical understanding are obligatory for this kind of 
examination. In addition, the observers need to rate the quality of an item in accordance. If possible, each item is weighed, unless the same or a very similar model already exists in the records. If the object is too heavy or bulky (e.g. washing machines), the missing weight data is retrieved in online research. For every collection point and waste stream, the data is compiled in a spreadsheet (see supplementary material) and aggregated afterwards. Figure 3 depicts the locations of visited collection points and their respective municipality classes.

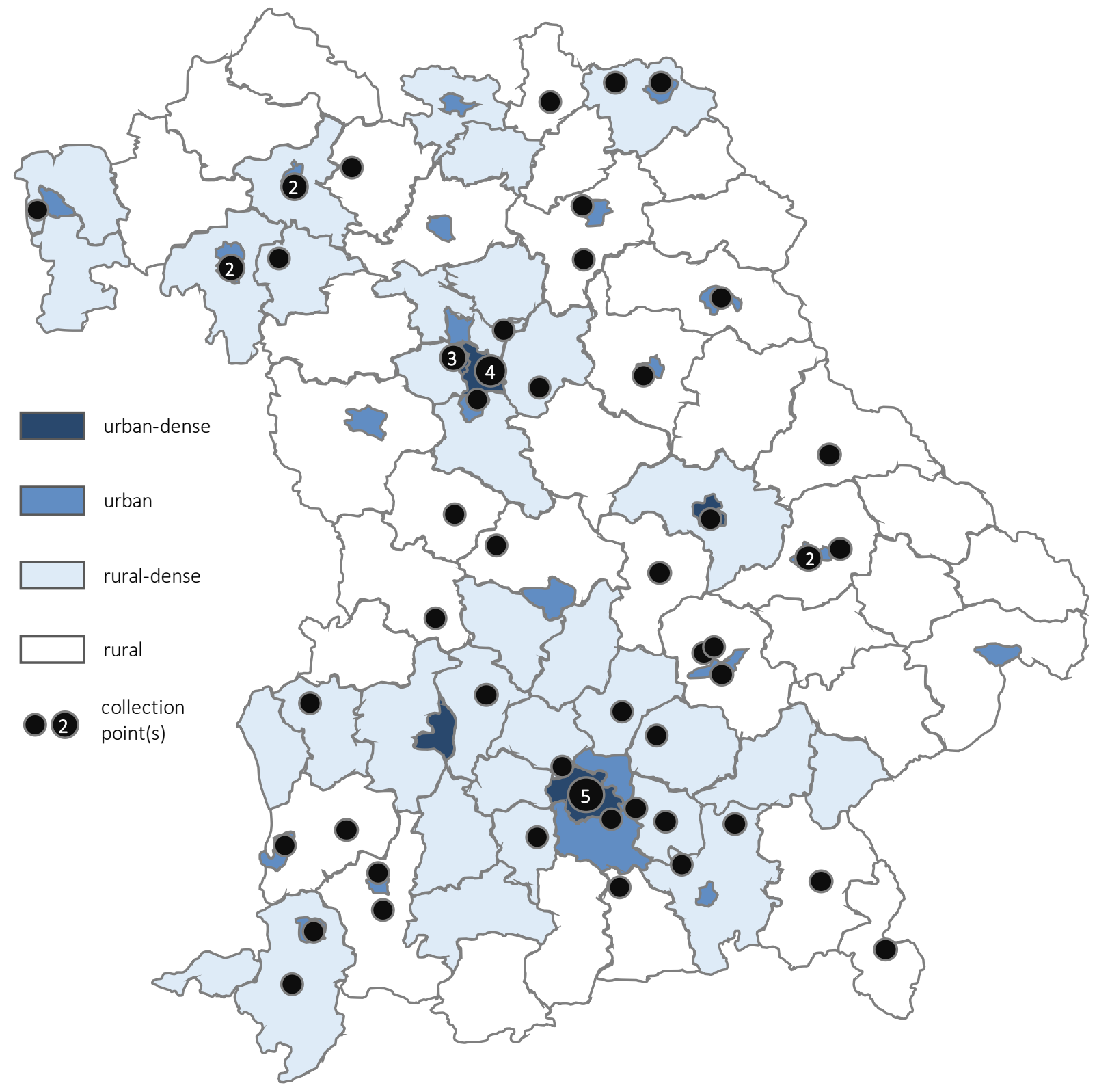

Figure 3. Municipality classes in Bavaria and assessed collection points (numbers indicate a set of assessed collection points in close proximity)

\subsection{Assessment of reuse potentials}

As indicated by the European Commission (2015), following an extensive literature review and stakeholder interviews, the quality of an item is the main success factor for the feasibility of reuse. The assigned quality of goods is based on a visual estimation of the overall condition of items assessed 
within six grades. We describe Q1 as "as good as new". Items graded Q2 may require cleaning to be acceptable in appearance. Q3 and Q4 apply to pieces with medium signs of wear e.g. heavier scratches or minor breakings, and noticeable defects. Q5 refers to heavy signs of usage, e.g. broken components that are integral to the product's function, while pieces rated Q6 may have lost their structural integrity entirely. Consequently, items with a quality of Q1 or Q2 require no or only minor preparation effort, while Q5 and Q6 can be considered unsuited for reuse. A more detailed definition of the six quality levels and the distinctions from one another are given in Appendix $A$, where we match our classification to the one by Parajuly and Wenzel (2017), who differentiate between the state of the product and appearance. We also refer to Guide and Van Wassenhove (2001) for the assessment via a six-level scheme, even though the verbal definitions of the quality levels Q1 to Q6 differ in some respects.

The analysis of the cause of the respective damage is complementary to the quality assessment. In this study, we evaluate collection points as possible sources for the preparation for reuse in Bavaria. Therefore, in terms of the damage cause (if existent for the respective quality level, see Appendix A), the most important information concerns the distinction between damages inflicted before the waste threshold (i.e. during use phase) or after the waste threshold (during insertion, transport, storage and pre-treatment, i.e. at the collection point). If a damage is inflicted after the waste threshold, we are able to quantify the benefit of taking actions to address these causes.

Resulting from a combined evaluation of the quality and the cause of damage of each item, we allocate the examined devices to three tiers according to the viability of preparation for reuse and its obstacles. Tier I potentials could be realized most readily, comprising all goods that could be prepared for reuse without taking further action. Tier II potentials require changes in the collection or storage system and comprise all goods that are damaged after having passed the waste threshold, implying that the piece would be reusable, had there been no avoidable damaging. Tier III potentials could become eligible for reuse after substantial changes in second-hand markets, incentives for improved value conservation by users, and other long-term efforts. Any piece not assigned to tiers I to III is considered inevitably inapt for preparation for reuse. Table 1 sums up the definition of tiers as a result of the evaluation of quality and cause of damage. We consider both characteristics, since the sole evaluation of the quality is insufficient for this assessment.

Table 1. Tiers of potential, subject to quality level (Q1-Q6) and damage cause

\begin{tabular}{lcll}
\hline Tier & Quality level & \multicolumn{2}{l}{ Damage cause } \\
\hline tier I & Q1, Q2 & $\&$ & n/a \\
tier II & Q3, Q4 & $\&$ & damage inflicted after waste threshold \\
tier III & Q3, Q4 & $\&$ & damage inflicted before waste threshold / not identifiable \\
inapt & Q5, Q6 & $\&$ & damage inflicted before waste threshold / not identifiable \\
\hline
\end{tabular}

\section{Results}

With the empirical collection of primary data at Bavarian collection points, we compile our findings in a database. Section 4 presents these findings. Fundamentally, the data can be aggregated in terms of 
waste streams and municipality classes. The three waste streams are described in terms of number of evaluated pieces and weight (section 4.1), quality (section 4.2), and the suspected cause of damage (section 4.3). Section 4.4 contains the quantification of theoretical potentials.

\subsection{Amounts of waste}

During the course of the primary data collection, we recorded 3,827 devices of WEEE, 1,132 pieces of used furniture, and 245 leisure goods. This amounts to 5,204 pieces in total, of which 1,530 have been examined at collection points in densely populated urban communes, 1,141 in urban communes, 1,349 in rural-dense areas, and 1,184 in rural areas.

The examined pieces of WEEE weigh $14.51 \mathrm{~kg}$ on average, significantly outweighing the other two waste streams, although WEEE only account for $1.3 \%$ of the total amount collected in Bavaria (BMUB, 2015; LfU, 2016). Since small WEEE make up $74.9 \%$ of the recorded electronic devices, the high average weight of WEEE is attributed to mainly large (household) equipment. Used furniture weighs $11.30 \mathrm{~kg}$ on average, leisure goods only $8.47 \mathrm{~kg}$. The average weight differences between the waste streams in total are statistically significant. Compared to the heavy electrical household goods, $53 \%$ of the furniture pieces are primarily made of wood or contain a significant fraction of wood. Table 2 summarizes key figures of the primary data collection for each waste stream and each class of municipality. Terms and items of Table 2 are defined in detail in sections 4.2 (quality levels) and 4.3 (damage causes).

Table 2. Primary data collection - Summary

\begin{tabular}{|c|c|c|c|c|c|c|}
\hline 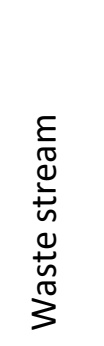 & $\begin{array}{l}\tilde{\mathscr{U}} \\
\frac{\pi}{U} \\
\mathbb{O} \\
\frac{\mathbb{U}}{<}\end{array}$ & $\begin{array}{l}\bar{d} \\
\sum_{0} \\
\stackrel{0}{0} \\
0 \\
\#\end{array}$ & $\begin{array}{l}\frac{1}{c 0} \\
\frac{.00}{0} \\
3 \\
Q\end{array}$ & 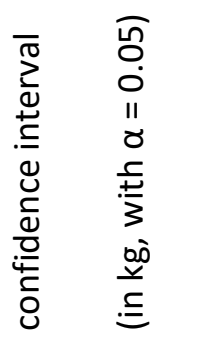 & 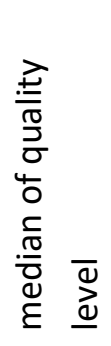 & 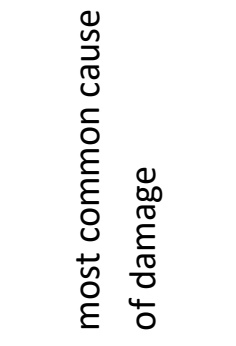 \\
\hline \multirow{7}{*}{ 岀 } & total & 3,827 & $14.51 \mathrm{~kg}$ & 13.96-15.07 & 4 & storage \\
\hline & small WEEE & 2,856 & $6.56 \mathrm{~kg}$ & $6.30-6.82$ & 4 & storage \\
\hline & large WEEE & 971 & $37.91 \mathrm{~kg}$ & $36.75-39.06$ & 4 & storage \\
\hline & urban-dense & 1,203 & $13.73 \mathrm{~kg}$ & $12.80-14.66$ & 3 & insertion \\
\hline & urban & 739 & $14.99 \mathrm{~kg}$ & $13.74-16.24$ & 5 & storage \\
\hline & rural-dense & 965 & $14.05 \mathrm{~kg}$ & $12.86-15.24$ & 4 & storage \\
\hline & rural & 920 & $15.64 \mathrm{~kg}$ & 14.49-16.79 & 4 & storage \\
\hline \multirow{5}{*}{ 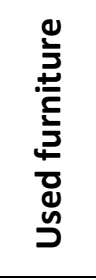 } & total & 1,132 & $11.30 \mathrm{~kg}$ & $10.22-12.38$ & 4 & use phase \\
\hline & urban-dense & 283 & $9.87 \mathrm{~kg}$ & $8.56-11.18$ & 4 & insertion \\
\hline & urban & 342 & $9.16 \mathrm{~kg}$ & $7.68-10.65$ & 4 & pre-treatment \\
\hline & rural-dense & 317 & $13.79 \mathrm{~kg}$ & $11.04-16.54$ & 4 & use phase \\
\hline & rural & 190 & $13.11 \mathrm{~kg}$ & 10.09-16.13 & 4 & insertion \\
\hline+0 & total & 245 & $8.47 \mathrm{~kg}$ & $7.44-9.50$ & 4 & use phase \\
\hline
\end{tabular}




\begin{tabular}{lrrrrr}
\hline urban-dense & 44 & $8.04 \mathrm{~kg}$ & $5.83-10.25$ & 2 & use phase \\
urban & 60 & $10.49 \mathrm{~kg}$ & $7.72-13.26$ & 4 & use phase \\
rural-dense & 67 & $10.14 \mathrm{~kg}$ & $8.44-11.84$ & 4 & pre-treatment \\
rural & 74 & $5.58 \mathrm{~kg}$ & $4.13-7.03$ & 3 & use phase \\
\hline
\end{tabular}

While the differences between classes of areas do not show statistical significance for WEEE, collected furniture is significantly heavier in the latter. The same is true for leisure goods in urban and ruraldense areas compared to rural areas. Differences in quality and damages, as indicated in Table 2, are further detailed in sections 4.2 and 4.3. A comprehensive account of underlying data of section 4 is given in the supplementary material.

\subsection{Quality levels of waste streams}

As the median is equal between all waste streams, the waste streams WEEE and used furniture show only minor differences in the observable quality level distribution. $19 \%$ of WEEE and $12 \%$ of used furniture have a good ( $Q 1$ or Q2) quality, while the majority ( $42 \%$ and $45 \%$ respectively) is unsuitable (Q5 or Q6) for reuse (Figure 4). Small WEEE have a larger fraction of well-preserved items (22\%) compared to large WEEE (11\%). In comparison, leisure goods are in a slightly better condition with $31 \%$ of well-preserved goods, and 31\% of quality Q5 or Q6.

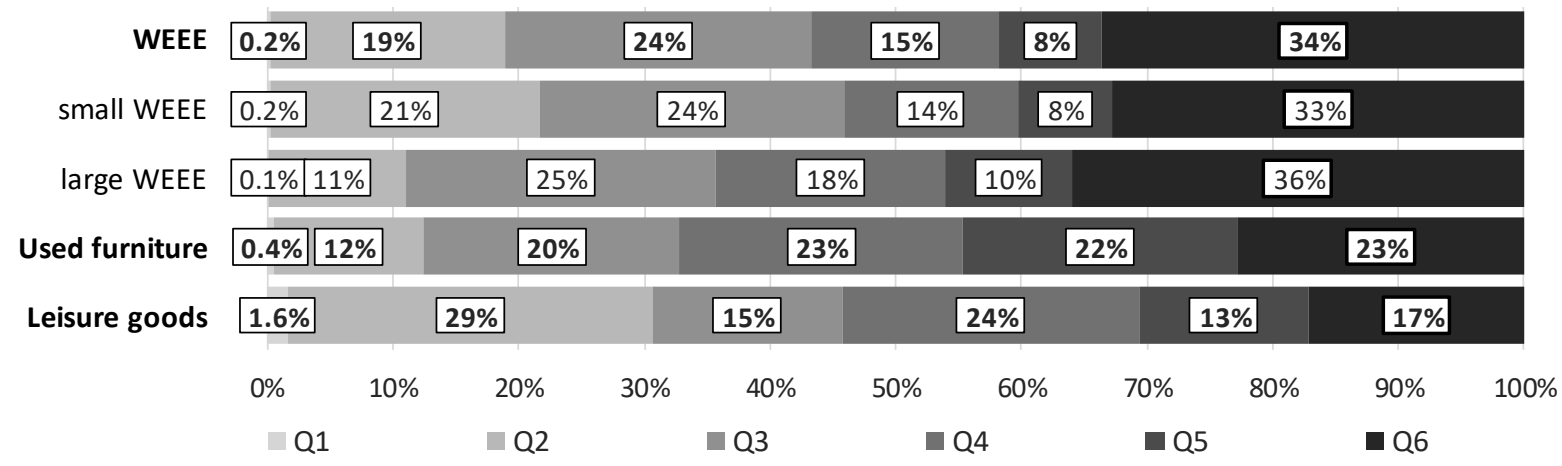

Figure 4. Distribution of estimated quality of waste streams

An overview of the distributions of quality ratings of all waste streams, including a distinction of small and large WEEE, in different classes of municipalities is given in Appendix $C$ and in the supplementary material. For WEEE, differences between goods collected in rural-dense or rural areas are only minor. Both have the median at Q4 and $38 \%$ and $37 \%$ of goods respectively are of low quality. WEEE in urbandense municipalities show a median of Q3 and a larger fraction at Q1 and Q2; the other quality levels are similarly distributed. Collected goods in urban areas are significantly worse, however, with a median of Q5 and 59\% of goods being unsuited for reuse. However unintuitive the significance of the differences among area classes may be, a similar observation can be made for used furniture and leisure goods, although with differing area classes standing out in comparison to the others. Even though the median is Q4 for each municipality class, in urban and rural areas the fraction of pieces with a good quality is the lowest with $4 \%$ and $8 \%$ respectively, compared to $24 \%$ and $14 \%$ in urbandense and rural-dense municipalities. In addition, rural-dense areas have the smallest fraction of goods with Q5 or Q6. For leisure goods, as for WEEE, urban-dense municipalities prevail as $61 \%$ of leisure 
goods are well preserved overall, while quality levels of Q5 and Q6 dominate for rural-dense areas ( $49 \%$ in total). That leads to the conclusion that measures for the improvement of the quality and thus the overall potential for the preparation for reuse need to be adjusted for and focused on different areas for each waste stream.

Lastly, we analyze the effects of different collection schemes. Figure 5 shows the distribution of quality levels (across all observed items) for collection points with no collection scheme, with fee-based collection, and with collection free of charge (sometimes limited to certain wastes, such as large household equipment). While the distribution of quality levels $Q 3$ to $Q 6$ is rather ambiguous, the fraction of items rated Q1 or Q2 increases with the existence of the possibility of collection from citizens, and again if this service is free of charge. This pattern regarding Q1 and Q2 can be observed for each waste stream analogously. This suggests that municipalities should establish free collection. However, in terms of the overall environmental advantageousness, this causality might not be unambiguous, e.g. if the previous owner disposes of the item due to this service instead of prolonging the use phase, or using other reuse channels.

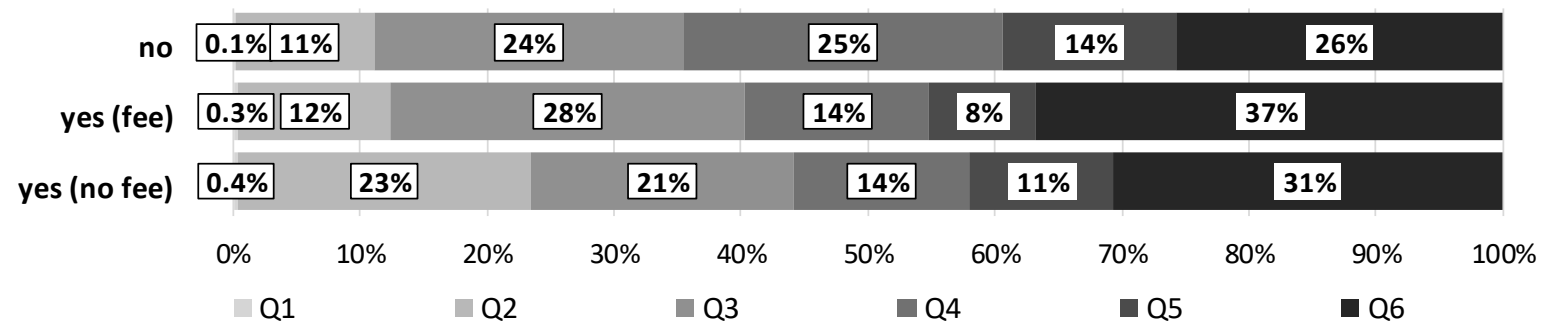

Figure 5. Distribution of estimated quality for collection points with free, fee-based, and no collection scheme

\subsection{Causal analysis of damages}

Figure 6 shows the suspected cause of damage for each waste stream. Values for each waste stream in each municipality class as well as a distinction between small and large WEEE can be found in the supplementary material. For WEEE, the prevalence of damages caused during storage is noticeable for every municipality class and for urban collection points in particular, of which the overwhelming majority (86\%) can be traced back to rain or other weather conditions. This is attributed to the vulnerability of electronics to exposition to weather conditions at the collection point, and applies to both small and large WEEE. This is in line with the common observation of the authors, that many collection containers at municipal collection points lack sufficient roofing for the protection of goods that are potentially in good working order. In contrast, e.g. leisure goods are far less prone to those causes of damage. Despite the comparably good condition of WEEE in urban-dense regions, the careless throw-in of WEEE into collection containers - independent of the prior condition of the inserted device - and the subsequent damaging of either the device itself or the devices stored in the container are identifiable issues. This is true particularly in urban-dense regions, and more so for small than for large WEEE (see supplementary material). This also applies to used furniture in rural and in urban-dense regions. In rural-dense areas, however, we identify pre-treatment of furniture and leisure goods to be the most pressing issue. Pre-treatment entails e.g. cutting off power cables of WEEE or, in the case of furniture and leisure goods, compressing wastes in wheeled loaders. In general, leisure goods are the waste stream with the highest share $(43 \%)$ of damages received during usage by the 
consumer as opposed to goods in good working order that receive the damage on site. In comparison, only $7 \%$ of damages of WEEE can conscientiously and solely be traced back to the use phase, which in turn implies that $93 \%$ of the damages of WEEE in our sample are inflicted after passing the waste threshold (regardless of whether prior damages existed or not). Like for the estimated quality level, the data suggests that different measures for increasing the fraction of municipal wastes eligible for reuse are of noticeably different effectiveness for different waste streams in different municipality classes.

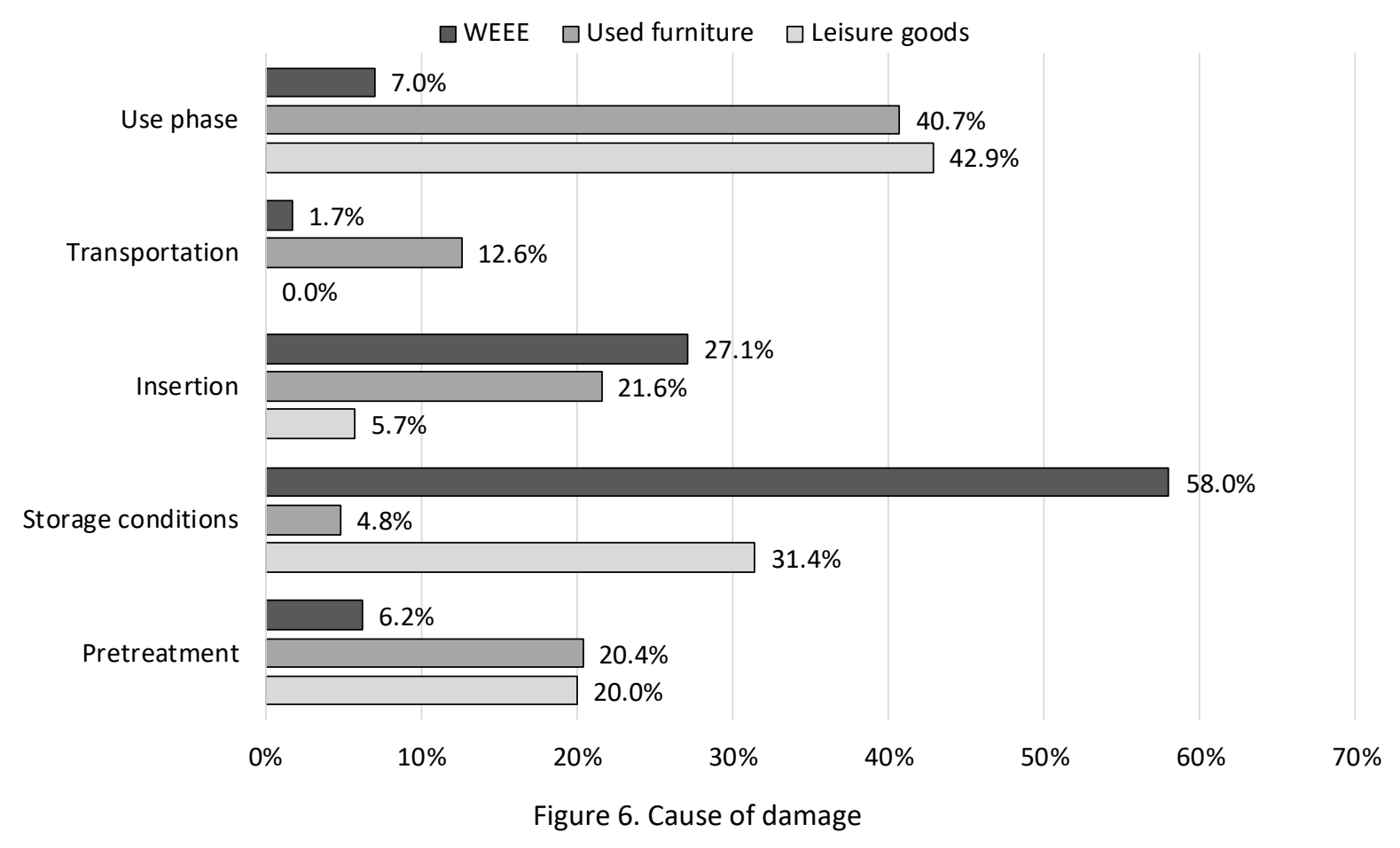

\subsection{Quantification of potentials}

Lastly, we quantify the potential of each waste stream for the preparation for reuse in Bavaria. The quantification is based on the previously conducted analyses, with the quantified potential being subdivided into three tiers, and extrapolated based on the total quantity of waste collected. In total, 721,873 metric tons of WEEE were collected in Germany in 2015, of which the status quo of preparation for reuse comprised 3,749 t. Using population (Eurostat, 2018) as explanatory variable, we project these values to 113,114 $\mathrm{t}$ and $587 \mathrm{t}$ respectively for Bavaria (BMUB, 2015). For used furniture, Dehoust et al. (2006) estimate an annual collection amount of roughly 7 million $t$ in Germany, of which between 350,000 $\mathrm{t}$ and 490,000 $\mathrm{t}$ are prepared for reuse (Lottner, 2015). For Bavaria, this amounts to $1,096,867 \mathrm{t}$ for collection and $54,843 \mathrm{t}$ to $76,781 \mathrm{t}$ for preparation for reuse. The mean value of $65,812 \mathrm{t}$ is equivalent to $6.0 \%$ of the collected amount. No data exists about collection and the reuse quotas of leisure goods. The potential of leisure goods is thus only quantified on a percentage basis.

Based on the overall collection amounts (if available) and the distribution of tiers (weight percentages), we quantify the theoretical potential of each waste stream. Figure 7 presents the aforementioned status quo and the defined tiers in comparison to the entire waste streams. As the results show, current reuse practice for WEEE in Bavaria (see above, approx. $587 \mathrm{t}$ ) covers only a vanishingly small 
fraction of devices that are, with regard to their condition, directly eligible for preparation for reuse $(16,361 \mathrm{t})$. Furthermore, the evaluation reveals structural flaws in the collection and storage practice. Up to $33,266 \mathrm{t}$ could theoretically be preserved in a condition that could allow for reuse, if damages after passing the waste threshold were avoided. Thus, up to $44 \%$, tiers I and II, could theoretically become reusable with reasonable effort. Even if these numbers represent a theoretical potential, they give a valuable indication on feasible leverages to unlock reuse potentials. With $47,848 \mathrm{t}$ classified tier III and 15,051 $\mathrm{t}$ being inapt for the preparation for reuse, $56 \%$ of all collected WEEE could justifiably be assigned to recycling. In this scenario, recycling would be far less prevalent compared to the preparation for reuse (cf. section 2) than it is the case today. We make similar observations for used furniture and leisure goods, with significant fractions assigned to tiers I and II (37\% for used furniture and $29 \%$ for leisure goods). It bears mentioning that this fraction is smaller for leisure goods, despite their excelling quality and low damage quota. This is attributed to the fact that the majority of those damages are inflicted before the damage threshold, i.e. during use phase, where possible leverages for unlocking the potential are fewer or less accessible.

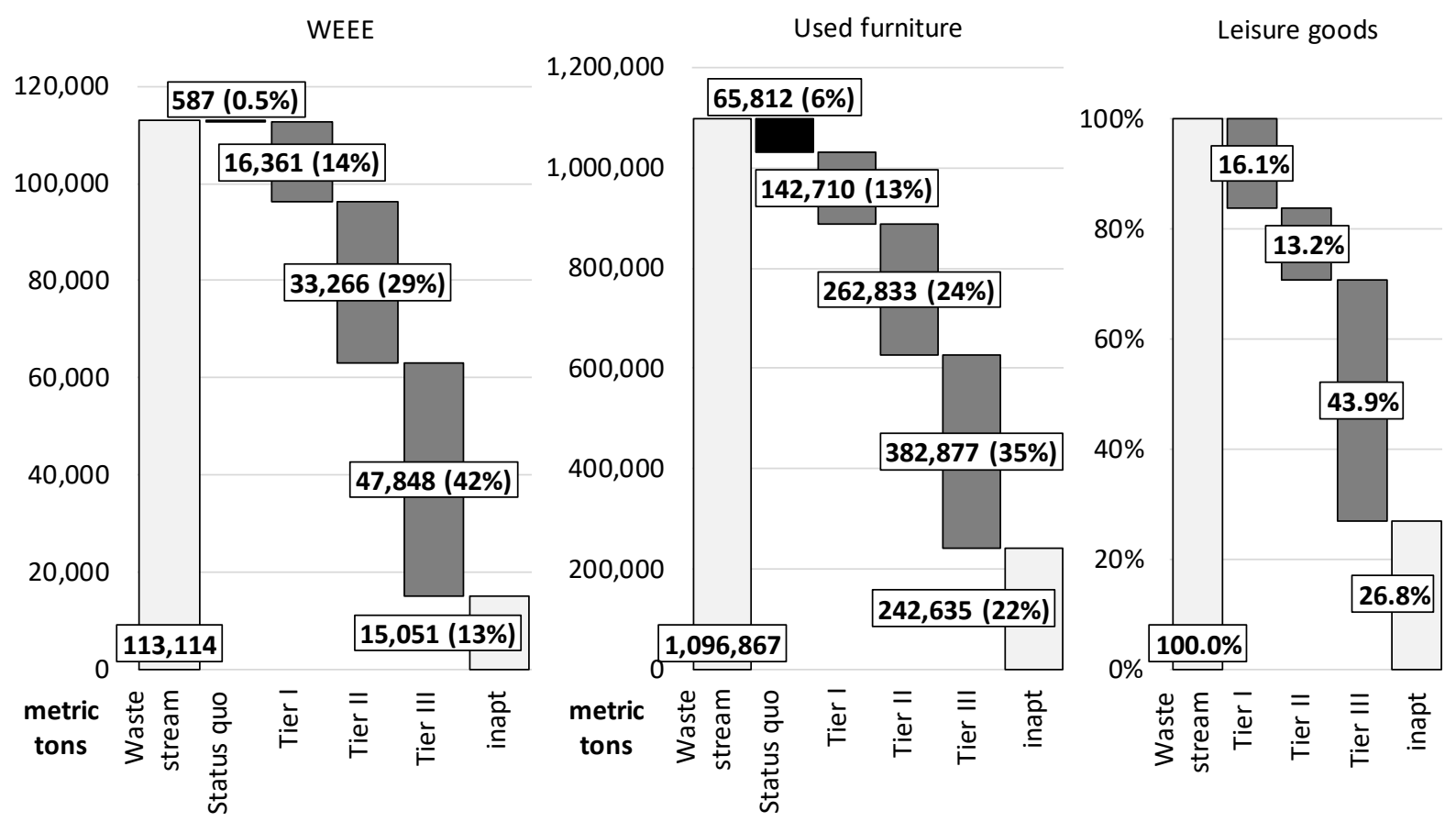

Figure 7. Status quo and theoretical potential for the preparation for reuse

\section{Discussion}

Literature addresses a variety of challenges that currently hinder the realization of these potentials (see section 2). Our causal analysis of damage and subsequent classification in three tiers allows for an identification of the most pressing issues for the preparation for reuse at collection points based on empirical data. Since (in terms of quality and damages) tier I devices could directly be prepared for reuse, and since tier II comprises all devices with damages caused during transport or on site, the most relevant insight from our study is the identification of those action recommendations that yield the 
highest potential for elevating devices from tier II to tier I. Here, we assume that respective damage causes could be avoided by taking the actions given in Table 3 .

Table 3. Action recommendations

\begin{tabular}{ll}
\hline Cause of damage & \multicolumn{1}{c}{ Action recommendation } \\
\hline Transportation & R1 Employment of value-preserving boxes instead of bulk cargo containers \\
Insertion & R2 Early separation of reusable devices \\
Storage conditions & R3 Employment of weatherproof and value-preserving containers \\
Pre-treatment & R4 Prohibiting pre-treatment \\
\hline
\end{tabular}

The identified actions are in accordance with the relevant literature (Broehl-Kerner et al., 2012; Neitsch et al., 2010; Sander et al., 2013; Spitzbart et al., 2009). The impact of the implementation of these recommendations differs between waste streams and municipality classes (Figure 8):

- For WEEE in general, implementing R3 yields the largest potential with $23,850 \mathrm{t}$ (71.7\% of tier II) that could be elevated from tier II to tier I and thus be immediately eligible for preparation for reuse. This priority is true for all municipality classes (except for urban-dense areas, where R3 is on a par with R2) and for urban municipalities in particular, where up to $86.4 \%$ of urban tier II devices could be positively affected by weatherproof and value-preserving storage. The fact that electronic devices are by far the most sensitive when exposed to weather conditions explains these numbers.

- Used furniture of tier II in general would mostly profit from implementing R2 and R4 with potential improvements of up to $103,997 \mathrm{t}$ and $94,030 \mathrm{t}$ respectively. In urban-dense and rural municipalities, R2 dominates the other recommendations by far. R4 in turn takes priority for ruraldense municipalities, where up to $73.1 \%$ of tier II furniture could be elevated to tier I if compressing furniture pieces in wheeled loaders did not take place. In urban municipalities, the potential of action recommendations is approximately equally distributed.

- The most pressing issue for leisure goods is storage (addressed by R3), with up to $74.0 \%$ of tier II leisure goods being positively affected. In comparison to WEEE, leisure goods are less sensitive to weather conditions, but rather require value-preserving containers.

Summarizing, municipalities in general should primarily implement R2 and R4 for increasing the potential of used furniture, while R3 takes priority for WEEE and leisure goods. Beyond that, R3 and R4 can be singled out for additional reasons. On the one hand, actions mainly addressing WEEE may justifiably be prioritized over others. WEEE is a waste stream of high interest in the European Union, entailing major environmental implications (Cucchiella et al., 2015). The fact that WEEE is the waste stream that is affected by R3 the most renders R3 even more important in comparison to the other recommendations in that light. $\mathrm{R} 4$ on the other hand is the action recommendation that requires the least changes to current practice and no additional infrastructure. On short notice, R4 can thus justifiably be prioritized over the other recommendations. 


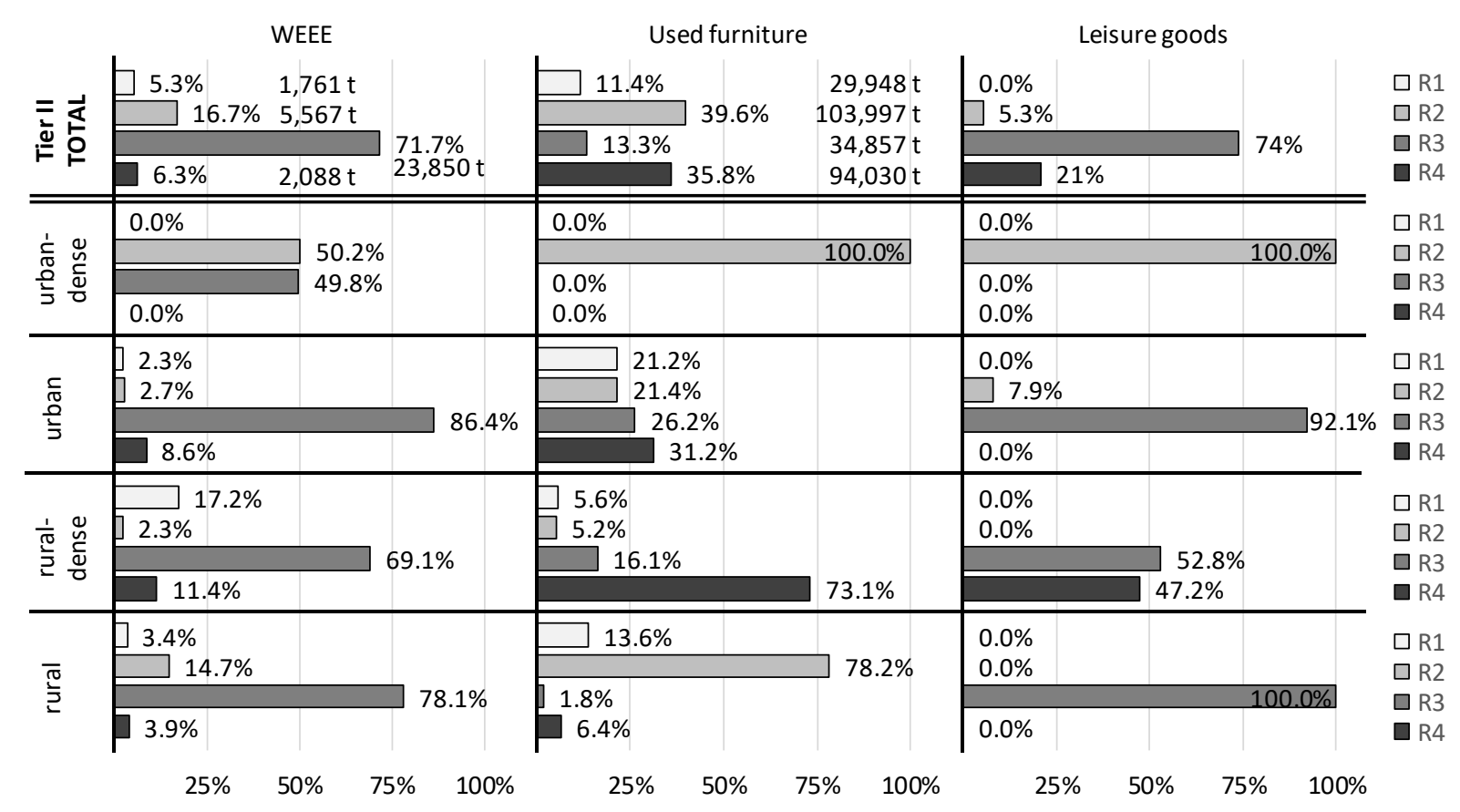

Figure 8. The effect of implementing action recommendations R1 to R4

Assuming a conservative scenario, where no actions are taken, only goods assigned to tier I (direct reuse) can be defined as reusable. In a moderate scenario, however, in which the identified issues are addressed by the described action recommendations, the reuse potential comprises items assigned to tiers I and II.

Existing literature (cf. section 2) assesses the reuse potential in a survey (Curran et al., 2007; WRAP, 2012), or based on "selective collection" (Bovea et al., 2016), therefore neglecting the damages that could occur through transport and on site. The moderate scenario (tiers I and II) includes those goods harmed during transport, storage, insertion, or pre-treatment on site. The resulting reuse potential ( $43 \%$ of WEEE, $37 \%$ of furniture, $29 \%$ of leisure goods) is therefore comparable to the findings from literature. Our results are in alignment with the ones from the residents' assessments of reuse potentials by WRAP (2012), as outlined in section 2. The visual inspections lead to higher estimations compared to our results. The reuse potential identified by Curran et al. (2007) is considerably higher for furniture (additional 21\%), slightly above our assessment for WEEE (additional 6\%), and not comparable for their definition of other bulky wastes. Bovea et al. (2016) identify $68 \%$ of small WEEE to be reusable. Parajuly and Wenzel (2017) assess the reusability of small WEEE collected at civic amenity sites in Denmark. The stated reuse potential of $22 \%$ is relatable to our tier I ( $14 \%$ of WEEE). Therefore, our assessment does not overestimate the reuse potential, but rather outlines how Bavarian collection points could contribute to unlocking existing reuse potentials.

However, two shortcomings bear mentioning here, which are outside of the broad scope of this study, and which our methodology cannot address. First, some correlations and interdependencies within the dataset cannot entirely be accounted for, e.g. the assessment of the quality of devices in different municipality classes does not shed light on the reasons for quality differences between them. An exceptionally good quality level in a municipality class could either be due to a well performing 
collection system, or due to an exceptionally short life cycle, i.e. the previous owner may have disposed of the device early and in a good condition, thus disregarding the waste hierarchy (see section 2). This uncertainty about causality and correlation is also why the observation regarding collection schemes (section 4.2, Figure 5) did not result in a (quantifiable) action recommendation. Second, we identify a theoretical potential for the preparation for reuse. This, however, does not imply that every device within that potential could indubitably be prepared for reuse in practice. Depending on the damage, repairing may not be possible technically, e.g. when necessary spare parts are unavailable. Furthermore, reuse is only feasible compared to recycling when existing demand justifies the efforts of preparation for reuse. For example, the costs of preparation for reuse may surpass the maximum possible revenue of the re-sold piece. For devices like CRT televisions, technological obsolescence and therefore non-existent demand may render preparation efforts futile. Lastly, devices like electric toothbrushes should be excluded from reuse for hygienic reasons, even if those devices are in perfect shape. Therefore, the identified potentials should rather be interpreted as an upper bound. For some WEEE, preparation for reuse may not even be unambiguously favorable environmentally. When replacing an old device with a new one, the increase in efficiency could potentially outweigh environmental impacts associated with the manufacturing of the new product. As indicated by WRAP (2011), Tecchio et al. (2016), Rüdenauer and Gensch (2007) and Downes et al. (2011), the evaluation of the environmentally most beneficial waste management option is device-specific and requires a holistic Life Cycle Assessment (LCA). Considering the concept of a circular economy, an analysis of the social aspects of reuse as well as of economic viability may complement an LCA-based evaluation

\section{Conclusion}

In this study, we develop a methodology for the quantitative assessment of potentially reusable wastes. We apply this framework in an empirical study at 61 waste collection points in Bavaria, collecting data of 3,827 WEEE, 1,132 pieces of used furniture, and 245 leisure goods. We find that between $13 \%$ and $16 \%$ of these waste streams could immediately be prepared for reuse, depending on the type of waste. A further potential of $13 \%$ to $29 \%$ could be unlocked through changes to the mode of collection, storage and the overall treatment of wastes at Bavaria collection points. We find that $19 \%$ of WEEE and $12 \%$ of used furniture have a good (Q1 or Q2) quality, while the majority (42\% and $45 \%$ respectively) is unsuitable for reuse. In comparison, leisure goods are in a statistically significantly better condition $31 \%$ of well-preserved goods, and $31 \%$ of quality level Q5 or Q6. The quality of the items differs between municipality classes. Within the causal analysis of damages, we differentiate between damages occurring during the use phase and after passing the waste threshold. Assuming that the latter could be avoided more easily, we derive four key action recommendations addressing damages during transportation, insertion, storage or pre-treatment. For WEEE and leisure goods, the largest potential $(23,850 \mathrm{t}$ and $74 \%$ respectively) could be elevated through the employment of weatherproof and value-preserving containers. Used furniture would mostly profit from implementing an early separation of reusable devices and the prohibition of densification in wheeled loaders, leading to an additional potential of up to $103,997 \mathrm{t}$ and $94,030 \mathrm{t}$ respectively.

This study was carried out with a broad scope regarding general differences between municipalities in mind. In the future, for realizing the identified potentials, more narrow research on specific collection 
sites or on specific wastes is necessary. Since we successfully applied our methodology within the scope of Bavaria, we aim at transferring it to different international regions as well as incorporating insights from Life Cycle Assessment of WEEE. This yields the facility to compare the status quo of current reuse practices and the influence of different national legislations.

\section{Funding}

The Bavarian State Ministry of the Environment and Consumer Protection supported this work as a part of a research project titled "Potentialabschätzung ausgewählter Abfallströme für die Vorbereitung zur Wiederverwendung" ("Estimation of the potential of selected waste streams for the Preparation for Reuse") [grant number $71 \mathrm{f}-U$ 8743. 1-2015/3-4-BAF01UKZA-69459].

\section{Appendix}

Appendix A. Description of quality levels in this study (left) and the definition by Parajuly and Wenzel (2017) (right)

\begin{tabular}{ll|ll}
\hline $\begin{array}{l}\text { Quality } \\
\text { level }\end{array}$ & Description & $\begin{array}{l}\text { State of the } \\
\text { product }\end{array}$ & Appearance \\
\hline Q1 & $\begin{array}{l}\text { as good as new } \\
\text { Qequires cleaning to be acceptable in appearance, very } \\
\text { Q2 }\end{array}$ & $\begin{array}{l}\text { complete } \\
\text { complete }\end{array}$ & $\begin{array}{l}\text { new } \\
\text { new/medium of wear }\end{array}$ \\
Q3 & $\begin{array}{l}\text { requires repair, medium signs of wear e.g. heavier } \\
\text { scratches or minor breakings, and noticeable defects } \\
\text { requires repair, heavy signs of wear e.g. heavier }\end{array}$ & missing parts & medium \\
Q4 & $\begin{array}{l}\text { scratches or breakings, and noticeable defects } \\
\text { heavy signs of usage, e.g. broken components that are }\end{array}$ & broken & medium/old \\
Q5 & $\begin{array}{l}\text { integral to the product's function } \\
\text { lost their structural integrity entirely }\end{array}$ & broken & old \\
\hline
\end{tabular}

Appendix B. Visited collection points and number of assessed pieces

\begin{tabular}{|c|c|c|c|c|c|c|c|c|}
\hline \# & Day & Date & $\begin{array}{l}\text { Class of } \\
\text { municipality }\end{array}$ & $\begin{array}{l}\text { Municipality } \\
\text { (Landkreis) }\end{array}$ & City & $\sum_{\#}^{\text {岀 }}$ & 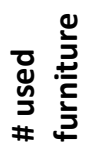 & 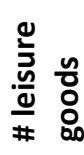 \\
\hline 1 & Wed & 15 Jun 2016 & rural-dense & Dachau & Dachau & 102 & 3 & 27 \\
\hline 2 & Wed & 15 Jun 2016 & rural-dense & Ebersberg & Kirchseeon & 23 & 4 & 13 \\
\hline 3 & Wed & 29 Jun 2016 & urban-dense & City of Munich & Munich & 106 & 13 & 9 \\
\hline 4 & Wed & 29 Jun 2016 & urban-dense & City of Munich & Munich & 186 & 3 & 18 \\
\hline 5 & Wed & 29 Jun 2016 & urban-dense & City of Munich & Munich & 91 & 9 & 29 \\
\hline 6 & Thu & 30 Jun 2016 & urban-dense & City of Munich & Munich & 282 & 0 & 24 \\
\hline 7 & Wed & $6 \mathrm{Jul} 2016$ & rural-dense & Munich & Ottobrunn & 37 & 1 & 0 \\
\hline 8 & Thu & 7 Jul 2016 & rural & Kelheim & Abensberg & 60 & 2 & 16 \\
\hline
\end{tabular}




\begin{tabular}{|c|c|c|c|c|c|c|c|}
\hline 9 & Thu & 7 Jul 2016 & rural & Donau-Ries & Rain & 166 & 6 \\
\hline 10 & Fri & $8 \mathrm{Jul} 2016$ & rural-dense & Ebersberg & Vaterstetten & 123 & 4 \\
\hline 11 & Fri & 8 Jul 2016 & rural-dense & Erding & Erding & 105 & 7 \\
\hline 12 & Fri & 8 Jul 2016 & rural-dense & Freising & Freising & 123 & 17 \\
\hline 13 & Wed & $13 \mathrm{Jul} 2016$ & rural & Eichstätt & Eichstätt & 69 & 3 \\
\hline 14 & Wed & $13 \mathrm{Jul} 2016$ & rural & Haßberge & Haßfurt & 33 & 13 \\
\hline 15 & Wed & 13 Jul 2016 & rural-dense & Schweinfurt & Bergrheinfeld & 35 & 1 \\
\hline 16 & Wed & $13 \mathrm{Jul} 2016$ & rural & Weißenburg-Gunzenhausen & Weißenburg i.Bay. & 125 & 2 \\
\hline 17 & Thu & 14 Jul 2016 & rural-dense & Aschaffenburg & Großostheim & 62 & 6 \\
\hline 18 & Thu & 14 Jul 2016 & urban & City of Regensburg & Regensburg & 113 & 0 \\
\hline 19 & Thu & $14 \mathrm{Jul} 2016$ & urban & City of Würzburg & Würzburg & 58 & 1 \\
\hline 20 & Thu & $14 \mathrm{Jul} 2016$ & urban & City of Würzburg & Würzburg & 38 & 1 \\
\hline 21 & Fri & $15 \mathrm{Jul} 2016$ & rural-dense & Kitzingen & Kitzingen & 44 & 8 \\
\hline 22 & Fri & $15 \mathrm{Jul} 2016$ & urban & Schweinfurt & Sennfeld & 81 & 1 \\
\hline 23 & Fri & $22 \mathrm{Jul} 2016$ & rural & Miesbach & Warngau & 40 & 19 \\
\hline 24 & Tue & $26 \mathrm{Jul} 2016$ & rural & Berchtesgadener Land & Bischofswiesen & 52 & 0 \\
\hline 25 & Tue & $26 \mathrm{Jul} 2016$ & rural & Traunstein & Traunstein & 78 & 8 \\
\hline 26 & Wed & $27 \mathrm{Jul} 2016$ & rural-dense & Rosenheim & Wasserburg a.Inn & 48 & 4 \\
\hline 27 & Thu & $28 \mathrm{Jul} 2016$ & rural-dense & Rosenheim & Tuntenhausen & 47 & 0 \\
\hline 28 & Fri & 29 Jul 2016 & urban-dense & City of Munich & Munich & 60 & 9 \\
\hline 29 & Fri & 29 Jul 2016 & rural-dense & Starnberg & Starnberg & 33 & 7 \\
\hline 30 & Mon & 1 Aug 2016 & urban & City of Memmingen & Memmingen & 44 & 1 \\
\hline 31 & Mon & 1 Aug 2016 & rural & Unterallgäu & Mindelheim & 46 & 4 \\
\hline 32 & Mon & 1 Aug 2016 & rural-dense & Oberallgäu & Immenstadt & 47 & 2 \\
\hline 33 & Tue & 2 Aug 2016 & rural & Ostallgäu & Marktoberdorf & 35 & 2 \\
\hline 34 & Wed & 3 Aug 2016 & rural-dense & Aichach-Friedberg & Aichach & 39 & 1 \\
\hline 35 & Wed & 3 Aug 2016 & rural-dense & Günzburg & Günzburg & 32 & 1 \\
\hline 36 & Thu & 4 Aug 2016 & urban & City of Kaufbeuren & Kaufbeuren & 46 & 1 \\
\hline 37 & Fri & 5 Aug 2016 & urban & City of Kempten & Kempten & 49 & 3 \\
\hline 38 & Mon & 8 Aug 2016 & urban & City of Straubing & Straubing & 36 & 0 \\
\hline 39 & Mon & 8 Aug 2016 & rural & Straubing-Bogen & Bogen & 42 & 1 \\
\hline 40 & Mon & 8 Aug 2016 & urban & City of Straubing & Straubing & 26 & 22 \\
\hline 41 & Tue & 9 Aug 2016 & rural-dense & Nürnberger Land & Altdorf b. Nürnberg & 36 & 0 \\
\hline 42 & Tue & 9 Aug 2016 & rural & Cham & Cham & 34 & 2 \\
\hline 43 & Wed & 10 Aug 2016 & urban & City of Amberg & Amberg & 42 & 3 \\
\hline 44 & Wed & 10 Aug 2016 & urban & City of Weiden i.d.OPf. & Weiden i.d.OPf. & 10 & 3 \\
\hline 45 & Thu & 11 Aug 2016 & rural & Bayreuth & Pegnitz & 30 & 0 \\
\hline 46 & Thu & 11 Aug 2016 & urban & City of Bayreuth & Bayreuth & 55 & 5 \\
\hline 47 & Thu & 11 Aug 2016 & urban & City of Hof & Hof & 22 & 3 \\
\hline 48 & Fri & 12 Aug 2016 & rural-dense & Hof & Naila & 29 & 1 \\
\hline 49 & Fri & 12 Aug 2016 & rural & Kronach & Kronach & 10 & 2 \\
\hline 50 & Thu & 18 Aug 2016 & rural & Landshut & Ergolding & 50 & 4 \\
\hline
\end{tabular}




\begin{tabular}{lllllllll}
51 & Fri & 19 Aug 2016 & rural & Landshut & Altdorf & 64 & 2 & 22 \\
52 & Fri & 19 Aug 2016 & rural & Landshut & Altdorf & 50 & 6 & 19 \\
53 & Mon & 22 Aug 2016 & urban-dense & City of Nuremberg & Nuremberg & 70 & 1 & 37 \\
54 & Tue & 23 Aug 2016 & urban-dense & City of Nuremberg & Nuremberg & 58 & 3 & 20 \\
55 & Tue & 23 Aug 2016 & urban-dense & City of Nuremberg & Nuremberg & 45 & 1 & 14 \\
56 & Tue & 23 Aug 2016 & urban-dense & City of Nuremberg & Nuremberg & 56 & 1 & 14 \\
57 & Wed & 24 Aug 2016 & rural-dense & Erlangen-Höchstadt & Eckental & 76 & 1 & 16 \\
58 & Wed & 24 Aug 2016 & urban-dense & City of Fürth & Fürth & 63 & 1 & 19 \\
59 & Thu & 25 Aug 2016 & urban-dense & City of Fürth & Fürth & 35 & 0 & 38 \\
60 & Fri & 26 Aug 2016 & urban-dense & City of Nuremberg & Nuremberg & 75 & 2 & 38 \\
61 & Thu & 8Sep 2016 & urban & City of Schwabach & Schwabach & 55 & 14 & 8 \\
\hline
\end{tabular}

Appendix C. Distribution of estimated quality of waste streams within different municipality classes

\begin{tabular}{lcccccc}
\hline & $\mathrm{Q} 1$ & $\mathrm{Q} 2$ & $\mathrm{Q} 3$ & $\mathrm{Q} 4$ & $\mathrm{Q} 5$ & $\mathrm{Q} 6$ \\
\hline WEEE & $\mathbf{0 . 2 \%}$ & $\mathbf{1 8 . 8 \%}$ & $\mathbf{2 4 . 3 \%}$ & $\mathbf{1 5 . 0 \%}$ & $\mathbf{8 . 2 \%}$ & $\mathbf{3 3 . 6 \%}$ \\
\hline urban-dense & $0.0 \%$ & $29.3 \%$ & $21.9 \%$ & $10.9 \%$ & $7.4 \%$ & $30.5 \%$ \\
urban & $0.1 \%$ & $6.5 \%$ & $20.8 \%$ & $13.7 \%$ & $9.2 \%$ & $49.7 \%$ \\
rural-dense & $0.4 \%$ & $19.7 \%$ & $28.7 \%$ & $13.2 \%$ & $6.5 \%$ & $31.5 \%$ \\
rural & $0.1 \%$ & $13.9 \%$ & $25.7 \%$ & $23.3 \%$ & $10.2 \%$ & $26.8 \%$ \\
\hline small WEEE & $0.2 \%$ & $21.4 \%$ & $24.2 \%$ & $13.8 \%$ & $7.6 \%$ & $32.7 \%$ \\
\hline urban-dense & $0.0 \%$ & $31.0 \%$ & $22.5 \%$ & $10.3 \%$ & $5.7 \%$ & $30.5 \%$ \\
urban & $0.2 \%$ & $8.6 \%$ & $22.1 \%$ & $13.8 \%$ & $9.7 \%$ & $45.6 \%$ \\
rural-dense & $0.4 \%$ & $23.4 \%$ & $25.7 \%$ & $11.8 \%$ & $6.5 \%$ & $32.1 \%$ \\
rural & $0.1 \%$ & $17.0 \%$ & $26.7 \%$ & $20.7 \%$ & $9.5 \%$ & $25.8 \%$ \\
\hline large WEEE & $0.1 \%$ & $10.9 \%$ & $24.6 \%$ & $18.3 \%$ & $10.0 \%$ & $36.0 \%$ \\
\hline urban-dense & $0.0 \%$ & $23.9 \%$ & $20.1 \%$ & $12.8 \%$ & $12.8 \%$ & $30.4 \%$ \\
urban & $0.0 \%$ & $0.0 \%$ & $17.0 \%$ & $13.2 \%$ & $7.7 \%$ & $62.1 \%$ \\
rural-dense & $0.4 \%$ & $9.6 \%$ & $36.8 \%$ & $16.9 \%$ & $6.5 \%$ & $29.9 \%$ \\
rural & $0.0 \%$ & $5.0 \%$ & $22.6 \%$ & $30.5 \%$ & $12.1 \%$ & $29.7 \%$ \\
\hline Used furniture & $\mathbf{0 . 4 \%}$ & $\mathbf{1 2 . 0 \%}$ & $\mathbf{2 0 . 3 \%}$ & $\mathbf{2 2 . 5 \%}$ & $\mathbf{2 1 . 8 \%}$ & $\mathbf{2 2 . 9 \%}$ \\
\hline urban-dense & $0.0 \%$ & $24.0 \%$ & $10.6 \%$ & $15.5 \%$ & $32.2 \%$ & $17.7 \%$ \\
urban & $0.9 \%$ & $3.5 \%$ & $27.2 \%$ & $25.1 \%$ & $21.9 \%$ & $21.3 \%$ \\
rural-dense & $0.6 \%$ & $12.9 \%$ & $22.1 \%$ & $25.6 \%$ & $16.1 \%$ & $22.7 \%$ \\
rural & $0.0 \%$ & $7.9 \%$ & $19.5 \%$ & $23.2 \%$ & $15.8 \%$ & $33.7 \%$ \\
\hline Leisure goods & $\mathbf{1 . 6 \%}$ & $\mathbf{2 9 . 0 \%}$ & $\mathbf{1 5 . 1 \%}$ & $\mathbf{2 3 . 7 \%}$ & $\mathbf{1 3 . 5 \%}$ & $\mathbf{1 7 . 1 \%}$ \\
\hline urban-dense & $6.8 \%$ & $54.5 \%$ & $11.4 \%$ & $9.1 \%$ & $6.8 \%$ & $11.4 \%$ \\
urban & $0.0 \%$ & $23.3 \%$ & $8.3 \%$ & $36.7 \%$ & $16.7 \%$ & $15.0 \%$ \\
rural-dense & $1.5 \%$ & $11.9 \%$ & $16.4 \%$ & $20.9 \%$ & $19.4 \%$ & $\mathbf{2 9 . 9 \%}$ \\
rural & $0.0 \%$ & $33.8 \%$ & $21.6 \%$ & $24.3 \%$ & $9.5 \%$ & $10.8 \%$ \\
\hline & & & & & & \\
\hline
\end{tabular}




\section{References}

BMUB, 2015. Daten zu Elektro- und Elektronikgeräten in Deutschland. http://www.bmub.bund.de/themen/wasser-abfall-boden/abfallwirtschaft/statistiken/elektround-elektronikaltgeraete/ (accessed 05 July 2018).

Bovea, M.D., Ibáñez-Forés, V., Pérez-Belis, V., Quemades-Beltrán, P., 2016. Potential reuse of small household waste electrical and electronic equipment: Methodology and case study. Waste Manag. 53, 204-217. doi: 10.1016/j.wasman.2016.03.038.

Broehl-Kerner, H., Elander, M., Koch, M., Vendramin, C., 2012. Second Life: Wiederverwendung gebrauchter Elektro- und Elektronikgeräte. https://www.umweltbundesamt.de/sites/default/files/medien/461/publikationen/4338.pdf (accessed 05 July 2018).

CIWM, 2016. Reuse in the UK and Ireland - a "State of the Nations" report for the Chartered Institution of Wastes Management. https://www.ciwm-journal.co.uk/downloads/Reuse-in-the-UK-andIreland-WEB.pdf (accessed 15 September 2018).

Cucchiella, F., D’Adamo, I., Lenny Koh, S.C., Rosa, P., 2015. Recycling of WEEEs: An economic assessment of present and future e-waste streams. Renew. Sustain. Energy Rev. 51, 263-272. doi: 10.1016/j.rser.2015.06.010.

Curran, A., Williams, I.D., Heaven, S., 2007. Management of household bulky waste in England. Resour. Conserv. Recycl. 51, 78-92. doi: 10.1016/j.resconrec.2006.08.003.

Dehoust, G., Buchert, M., Jenseit, W., Schulze, F., Hermann, A., Ferenz, J., Giegrich, J., Fehrenbach, H., Vogt, R., 2006. Development of the Closed Cycle and Waste Management Policy Towards a Sustainable Substance Flow and Resources Policy, FKZ 90531411. Sub-project "Identification of Relevant Substances and Materials for a Substance Flow-Oriented Resource Conserving Waste Management". https://www.oeko.de/oekodoc/323/2006-021-en.pdf (Accessed 24 September 2018).

Devoldere, T., Willems, B., Duflou, J.R., Dewulf, W., 2009. The eco-efficiency of reuse centres critically explored - the washing machine case. Int. J. Sustain. Manuf. 1(3), 265-285. doi: 10.1504/IJSM.2009.023974

Directive 2008/98/EC of the European Parliament and of the Council of 19 November 2008 on waste and repealing certain Directives. 22.11.2008, OJ L 312, 3-30.

Directive 2012/19/EU of the European Parliament and of the Council of 4 July 2012 on waste electrical and electronic equipment (WEEE). 27.7.2012, OJ L 197, 38-71.

Downes, J., Thomas, B., Dunkerley, C., Walker, H., 2011. Longer Product Lifetimes Summary Report. http://www.google.com/url?sa=t\&rct=j\&q=\&esrc=s\&source=web\&cd=1\&ved=0ahUKEwiF0Xmsu7bAhXrbZoKHfgTAYIQFggtMAA\&url=http\%3A\%2F\%2Frandd.defra.gov.uk\%2FDocument.as px\%3FDocument\%3DSummaryReport.pdf\&usg=AOvVaw2z7NOU2oQfzCK7XsrREyuC (accessed 05 July 2018).

European Commission, 2015. Study on WEEE recovery targets, preparation for re-use targets and on the method for calculation of the recovery targets. http://ec.europa.eu/environment/waste/weee/pdf/16.\%20Final\%20report_approved.pdf (accessed 05 July 2018).

Eurostat, 2018. Population statistics at regional level. http://ec.europa.eu/eurostat/statisticsexplained/index.php/Population_statistics_at_regional_level (accessed 05 July 2018). 
Eurostat, 2018. Waste statistics - electrical and electronic equipment. https://ec.europa.eu/eurostat/statistics-explained/index.php/Waste_statistics__electrical_and_electronic_equipment\#EEE_put_on_the_market_and_WEEE_collected_in_the _EU (accessed 24 September 2018).

Ghisellini, P., Cialani, C., Ulgiati, S., 2016. A review on circular economy: The expected transition to a balanced interplay of environmental and economic systems. J. Clean. Prod. 114, 11-32. doi: 10.1016/j.jclepro.2015.09.007.

Grunow, M., Gobbi, C., 2009. Designing the reverse network for WEEE in Denmark. CIRP Ann. - Manuf. Technol. 58 (1), 391-394. doi: 10.1016/j.cirp.2009.03.036.

Guerra González, J., 2013. Vorbereitung zur Wiederverwendung: Regelung und Regelungsbedarf Umsetzungs- und Erfolgsaussichten. https://www.leuphana.de/fileadmin/user_upload/Forschungseinrichtungen/professuren/energ ie-und-umweltrecht/Schriftenreihe/NR_-_Nr._3_Guerra_WWV_def.pdf (accessed 05 July 2018).

Guide V.D.R., Van Wassenhove, L.N., 2001. Managing Product Returns for Remanufacturing. Prod. Oper. Manag. 10(2), 142-155. doi: 10.1111/j.1937-5956.2001.tb00075.x.

Haas, W., Krausmann, F., Wiedenhofer, D., Heinz, M., 2015. How circular is the global economy?: An assessment of material flows, waste production, and recycling in the European union and the world in 2005. J. Ind. Ecol. 19, 765-777. doi: 10.1111/jiec.12244.

Hutner, P., Helbig C., Stindt D., Thorenz A., Tuma A., 2018. Transdisciplinary development of a life-cycle based approach to measure and communicate waste prevention effects in local authorities. J. Ind. Ecol., in press.

Hutner, P., Thorenz, A., Tuma, A., 2017. Waste prevention in communities: A comprehensive survey analyzing status quo, potentials, barriers and measures. J. Clean. Prod. 141, 837-851. doi: 10.1016/j.jclepro.2016.09.156.

Johnson, M., McMahon, K., Fitzpatrick, C., 2015. Research of Upcycling supports to increase re-use , with a focus on Waste Electrical and Electronic Equipment. http://www.epa.ie/researchandeducation/research/researchpublications/researchreports/Res earch_Report_241.pdf (accessed 15 September 2018).

Kissling, R., Coughlan, D., Fitzpatrick, C., Boeni, H., Luepschen, C., Andrew, S., Dickenson, J., 2013. Success factors and barriers in re-use of electrical and electronic equipment. Resour. Conserv. Recycl. 80, 21-31. doi: 10.1016/j.resconrec.2013.07.009.

KrWG - Reorganising the Law on Closed Cycle Management and Waste of February 24th 2012. http://www.bmu.de/fileadmin/Daten_BMU/Download_PDF/Abfallwirtschaft/kreislaufwirtschaf tsgesetz_en_bf.pdf (accessed 05 July 2018).

Kunz, N., Mayers, K., Van Wassenhove, L.N., 2018. Stakeholder Views on Extended Producer Responsibility and the Circular Economy. Calif. Manag. Rev. 60, 45-70. doi: 10.1177/0008125617752694.

Lapkin, A., Joyce, L., Crittenden, B., 2004. Framework for evaluating the "greenness" of chemical processes: case studies for a novel VOC recovery technology. Environ. Sci. Technol. 38, 5815 5823. doi: 10.1021/es035414h.

LfU - Bayrisches Landesamt für Umwelt, 2016. Hausmüll in Bayern. Bilanzen 2015. http://www.abfallbilanz.bayern.de/doc/Abfallbilanz2015.pdf (accessed 05 July 2018).

Löhle, S., Bartnik, S., Ehrenbrink, M., Müller, M., 2016. Förderung der Vorbereitung zur Wiederverwendung von Elektro(nik)altgeräten. 
https://www.nabu.de/imperia/md/content/nabude/konsumressourcenmuell/160801-nabuvzwv-studie.pdf (accessed 15 September 2018).

Lottner, U., 2015. infoBlätter Kreislaufwirtschaft. Gebrauchtmobiliar zur Wieder- und Weiterverwendung.

https://www.abfallratgeber.bayern.de/publikationen/entsorgung_einzelner_abfallarten/doc/ge braucht.pdf (accessed 05 July 2018).

Neitsch, M., Spitzbart, M., Hammerl, B., Schleich, B., 2010. Umsetzungskonzept zur Implementierung des Gebotes der „Wiederverwendung" gemäß ARL2008 in Österreich. http://www.repanet.at/reuse-toolbox/re-use-repathek/umsetzungskonzept-zur-implementierung-des-gebotes-derwiederverwendung-gemaess-arl2008-in-oesterreich/ (accessed 05 July 2018)

O'Connell, M.W., Hickey, S.W., Fitzpatrick, C., 2012. Evaluating the sustainability potential of a white goods refurbishment program. Sustain. Sci. 8, 529-541. doi: 10.1007/s11625-012-0194-0.

Ongondo, F.O., Williams, I.D., Cherrett, T.J., 2011. How are WEEE doing? A global review of the management of electrical and electronic wastes. Waste Manag. 31, 714-730. doi: 10.1016/j.wasman.2010.10.023.

Parajuly, K., Wenzel, H., 2017. Potential for circular economy in household WEEE management. J. Clean. Prod. 151, 272-285. doi: 10.1016/j.jclepro.2017.03.045.

Pladerer, C., Meissner, M., Huber, T., Pflügl, M., Bauer, D., 2008. ruso - Reuse Shops Oberösterreich. http://www.ecology.at/files/berichte/E10.870.pdf (accessed 15 September 2018).

Pérez-Belis, V., Bovea, M.D., Ibáñez-Forés, V., 2015. An in-depth literature review of the waste electrical and electronic equipment context: Trends and evolution. Waste Manag. Res. 33, 3-29. doi: $10.1177 / 0734242 \times 14557382$.

Quariguasi Frota Neto, J., Walther, G., Bloemhof. J., van Nunen, J., Spengler, T., 2010. From closedloop to sustainable supply chains: the WEEE case. Int. J. Prod. Res. 48(15), 4463-4481. doi: 10.1080/00207540902906151.

Queiruga, D., Queiruga-Dios, A., 2015. The Reuse of Waste Electrical and Electronic Equipment (WEEE). A Bibliometric Analysis. Int. J. Waste Resour. 05. doi: 10.4172/2252-5211.1000177.

Rüdenauer, I., Gensch, C., 2007. Environmental and economic evaluation of the accelerated replacement of domestic appliances: Case study refrigerators and freezers. https://www.oeko.de/oekodoc/271/2005-016-en.pdf (accessed 05 July 2018).

Sander, K., Schilling, S., Jepsen, D., Gsell, M., 2013. Förderung der Wiederverwendung Erfahrungen aus Schleswig-Holstein. https://www.oeko.de/oekodoc/2026/2013-611-de.pdf (accessed 05 July 2018).

Schomerus, T., Fabian, M., Fouquet, D., Nysten, J.V., 2014. Juristisches Gutachten über die Förderung der Vorbereitung zur Wiederverwendung von Elektro-Altgeräten im Sinne der zweiten Stufe der Abfallhierarchie.

http://www.umweltbundesamt.de/sites/default/files/medien/378/publikationen/texte_36_20 14_komplett_0.pdf (accessed 05 July 2018).

Spitzbart, M., Thaler, A., Stachura, M., 2009. Leitfaden für die Wiederverwendung von Elektroaltgeräten in Österreich: Ergebnis der ReUse-Plattform. http://www.kerp.at/uploads/media/KERP___ReuseLeitfaden.pdf (accessed 05 July 2018).

Tecchio, P., Ardente, F., Mathieux, F., 2016. Analysis of durability, reusability and reparability Application to washing machines and dishwashers. doi: 10.2788/51992. 
UBA - Umweltbundesamt, $2014 . \quad$ Waste regulations. https://www.umweltbundesamt.de/en/topics/waste-resources/waste-management/wasteregulations (accessed 05 July 2018).

Von Gries, N., Henning, W., 2017. Schaffung einer Datenbasis zur Erfassung der Mengen von in Deutschland wiederverwendeten Produkten. https://www.umweltbundesamt.de/sites/default/files/medien/1968/publikationen/2017-0117_texte_04-2017_zwischenbericht_mengen-wiederverwendete-produkte_v2.pdf (accessed 15 September 2018).

Williams, I.D., Taylor, C., 2004. Maximizing household waste recycling at civic amenity sites in Lancashire, England. Waste Manag. 24, 861-874. doi:10.1016/j.wasman.2004.02.002.

WRAP, 2011. Realising the Reuse Value of Household WEEE. http://www.wrap.org.uk/sites/files/wrap/WRAP\%20WEEE\%20HWRC\%20summary\%20report.p df (accessed 05 July 2018).

WRAP, 2012. Composition of kerbside and HWRC bulky waste. http://www.wrap.org.uk/content/bulky-waste-technical-report (accessed 15 September 2018).

Zacho, K.O., Bundgaard, A.M., Mosgaard, M.A., 2018. Constraints and opportunities for integrating preparation for reuse in the Danish WEEE management system. Resour. Conserv. Recycl. 138, 13-23. doi: 10.1016/j.resconrec.2018.06.006. 